\title{
State-of-the-Art Imaging in Human Chordoma of the Skull Base
}

\author{
Rene G. C. Santegoeds ${ }^{1} \cdot$ Yasin Temel $^{2} \cdot$ Jan C. Beckervordersandforth $^{3}$ • \\ Jacobus J. Van Overbeeke ${ }^{2} \cdot$ Christianne M. Hoeberigs ${ }^{1}$
}

Published online: 3 April 2018

(C) The Author(s) 2018

\begin{abstract}
Purpose of Review Chordoma are rare tumours of the axial skeleton which occur most often at the base of the skull and in the sacrum. Although chordoma are generally slowgrowing lesions, the recurrence rate is high and the location makes it often difficult to treat. Both computed tomography (CT) and magnetic resonance imaging (MRI) are crucial in the initial diagnosis, treatment planning and post-treatment follow-up.

Recent Findings Basic MRI and CT characteristics of chordoma were described in the late 1980s and early 1990s. Since then, imaging techniques have evolved with increased resolution and new molecular imaging tools are rapidly evolving. New imaging tools have been developed not only to study anatomy, but also physiologic changes and characterization of tissue and assessment of tumour biology. Recent studies show the uptake of multiple PET tracers in chordoma, which may become an important aspect in the diagnosis, follow-up and personalized therapy.

Summary This review gives an overview of skull base chordoma histopathology, classic imaging characteristics, radiomics and state-of-the-art imaging techniques that are
\end{abstract}

This article is part of the Topical collection on ENT Imaging.

Rene G. C. Santegoeds

Remco.santegoeds@mumc.nl

1 Department of Radiology, Maastricht University Medical Center, P. Debyelaan 25, 6229 HX Maastricht, The Netherlands

2 Department of Neurosurgery, Maastricht University Medical Center, Maastricht, The Netherlands

3 Department of Pathology, Maastricht University Medical Center, Maastricht, The Netherlands now emerging in diagnosis, treatment planning and disease monitoring of skull base chordoma.

Keywords Chordoma - Benign notochordal cell tumour (BNCT) · Chondrosarcoma · Computed tomography (CT) · Magnetic resonance imaging (MRI) · Positron emission tomography (PET) · Diffusion-weighted imaging (DWI)

\section{Introduction}

Chordoma are rare tumours of the axial skeleton that occur most at the base of the skull and in the sacrum. Chordoma are thought to arise from remnants of the foetal notochord, that remain in the axial skeleton throughout life and may undergo malignant transformation into chordoma at any age $[1,2]$. The incidence is estimated around 0.08 per 100,000 per year [3, 4], and chordoma account for around $6 \%$ of primary bone tumours [5]. The localization is distributed around $1 / 3 \mathrm{rd}$ skull base, $1 / 3 \mathrm{rd}$ spine and $1 / 3 \mathrm{rd}$ sacrum [3]. Although the overall $10 \mathrm{y}$ survival rate is around 55\% [6], the 5- and 10-year recurrence rates are reported up to, respectively, 53 and $88 \%$ [7]. The most accepted therapy is resection as complete as possible. This is challenging at the level of the skull base due to surrounding critical structures including the optic system, carotid artery and brain stem. After the surgery, radiation with particle therapy has become the golden standard, i.e. proton beam or carbon-ion therapy [8]. Chordoma are resistant to conventional chemotherapy [9]. Therefore, adequate diagnosis and preoperative planning are crucial for maximal resection rate. This article describes the radiologic characteristics of chordoma and differential diagnosis and gives an overview of evolving imaging studies and future perspectives in radiology of this tumour 
entity. Understanding the histopathologic features and molecular markers is crucial for interpretation of imaging characteristics, especially in tumours with heterogeneous content like chordoma. Therefore, this review starts with a brief overview of the histopathology of these tumours.

\section{Histology and Immunohistochemistry}

Macroscopically, chordoma appear as a white-grey soft, lobulated, gelatinous tumour with dens fibrous trabeculae [10-12]. Mucoid substance, necrotic areas, recent and old haemorrhages are found in the tumour, as well as calcification and sequestration of bone fragments [13]. The soft tissue is frequently surrounded by an incomplete pseudocapsule, with pressured surrounding tissue mimicking a true capsule [11].

There have been three different histological variants of chordoma described: classical (conventional), chondroid and dedifferentiated [14]. Dedifferentiated chordoma comprise $<4 \%$ of all chordoma subtypes [15], but have a much poorer prognosis [15-18]. The poorly differentiated chordoma are a particularly aggressive tumour with a predilection for the paediatric population [19]. Poorly differentiated or dedifferentiated chordoma may develop de novo, or transform as recurrent chordoma after surgery or radiotherapy [20, 21]. Although a study by Heffelfinger et al. [22] suggested that the chondroid variant has a better prognosis than classical chordoma, other studies [23-28] contradicted these results. Rosenberg et al. [27] redefined the histopathologic characteristics of the chondroid chordoma and concluded that part of the chondroid chordoma that were studied by Heffelfinger et al. [22] were actually low-grade chondrosarcoma. This makes a vital difference since chondrosarcoma tend to have a better prognosis than chordoma [29, 30].

All chordoma subtypes display a heterogeneous cytology. The predominant cell types are large cells which contain prominent solitary or multiple vacuoles, also called physaliphorous cells. These vacuoles are rich in mucopolysaccharides [22, 31, 32]. The smaller cells are non-vacuolated and referred to as stellate cells. The physaliphorous cells are arranged in sheets, cords or float singly within the abundant myxoid stroma and may be separated by fibrous bands [33, 34]. As seen macroscopically, chordoma are very heterogenous tumours with regional differences varying from areas of necrosis, to areas of mucoid degeneration, cartilage and connective tissue. Final diagnosis is made with immunohistochemistry. Chordoma show a unique immunohistochemical pattern with positive staining with antibodies against S100 protein, vimentin, low molecular cytokeratins and epithelial membrane antigen $[22,26]$. The chondroid variant of chordoma is histologically similar to chondrosarcoma, and also share an immunoreactivity with antibodies against S100, which makes it challenging in differentiating between the two tumours. More recent studies show that brachyury, a T-box transcription factor, is a novel discriminating marker for chordoma [35, 36]. However, the role of brachyury in the pathogenesis of chordoma is still not completely understood.

\section{CT and MR Imaging Characteristics}

Chordoma present as osteolytic, destructive lesions with associated cortical destruction and soft tissue extension. Chordoma of the skull base are generally located in the upper half of the clivus and often extends to the lower half of the clivus, posterior clinoid process, cavernous sinus and occipital condyle [37]. Sometimes chordoma may also arise at the craniovertebral junction and involve the atlas and axis (see Fig. 1). The bulk of the tumour is usually located in the midline of the patient. [38] Extraosseous extension of the tumour can occur in all directions, from the nasal cavity to indenting of the pons, also called thumbsign [39]. Chordoma are slow-growing lesions [1]. Although case reports have described intradural location, chordoma are usually extradural lesions [40, 41].

On non-contrast CT, chordoma typically appear as wellcircumscribed, hypoattenuating, heterogeneous lesion with extensive lytic bone destruction [42, 43]. The bulk of the tumour is usually hyperattenuating relative to the adjacent neuronal axis [44]. It may be difficult to distinguish between intratumoral calcifications, which are characteristic of the chondroid variant of chordoma [14], and sequestered fragments of the destroyed clival bone. There may be some separated areas of low attenuation within the tumour, probably also related to mucinous content [45].

The MRI characteristics of chordoma with the standard MRI sequences have been well described as early as the late 1980s and early 1990s [46-50]. Since then, MRI has come a long way. New developments in acquisition techniques, MRI detectors and the use of higher magnetic fields are pushing MRI resolution to almost histological levels. Chordoma can have variable signal intensity on T1, classically generally low-to-intermediate signal intensity, with sometimes small foci of hyperintensity, correlated with mucus or haemorrhage [46]. Classic chordoma show high T2 signal intensity with heterogeneous hypointensity, which may also be associated with mucous, haemorrhage and also calcification. The presence of haemorrhagic foci or calcification can be confirmed with gradient echo images or susceptibility weighted imaging (SWI), showing susceptibility artefacts [46]. Low signal intensity septations may be seen, which may correlate with areas of necrosis or 

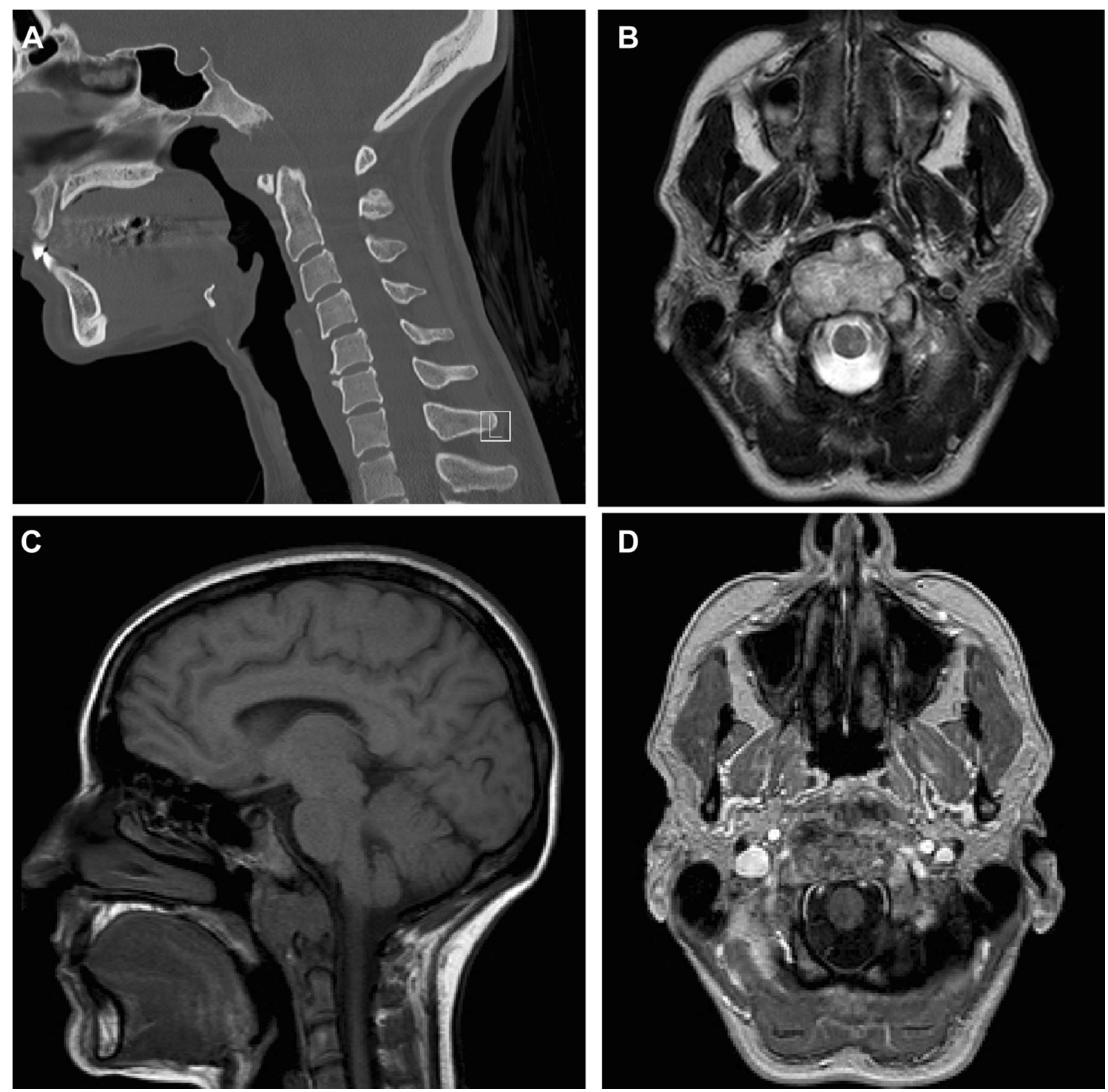

Fig. 1 Chordoma. Imaging of a chordoma at the craniocervical junction. Computed tomography (a) shows lysis of the lower clivus. Axial T2-weighted imaging (b) shows a heterogenous, mostly hyperintense mass at the midline of the lower clivus. There is

cartilage seen in histology. Poorly differentiated chordoma may show different imaging characteristics. Yeom et al. [51•] showed hypointensity on T2-weighted images in three poorly differentiated chordoma. However, there is a lack of studies in larger poorly differentiated chordoma cohorts. Chordoma typically show moderate to marked Gadolinium contrast enhancement with honeycomb appearance, with linear areas of non-enhancement [52]. This may also be explained with the areas of necrosis, connective tissue or cartilage in the tumour at histology. Fat suppression imaging with suppression of the fatty bone marrow of the clivus may be useful in the delineation of clival chordoma [44]. Figures 1 and 2 show typical anterior extension to the oropharynx. The mass is hypointense on T1weighted imaging (c) with heterogenous contrast enhancement (d). Pathologic examination confirmed the diagnosis of chordoma

imaging characteristics of chordoma. More advanced imaging techniques will be discussed later.

Metastases occur in 6-30\% of all chordoma [53-56]. Common metastatic sites are lungs, bone, skin and liver [53, 55-57]. Chordoma metastases have similar imaging characteristics as the primary site. On CT images, chordoma metastases are generally low-density masses, as chordoma are typically osteolytic lesions. Similar to MRI of the primary tumour, chordoma metastasis show low-tointermediate signal intensity on T1, high signal intensity on T2-weighted images and contrast enhancement in almost all cases [54]. Diffusion-weighted images show high signal intensity of the chordoma metastasis, most likely due to the gelatinous structure of chordoma [54]. The importance of 

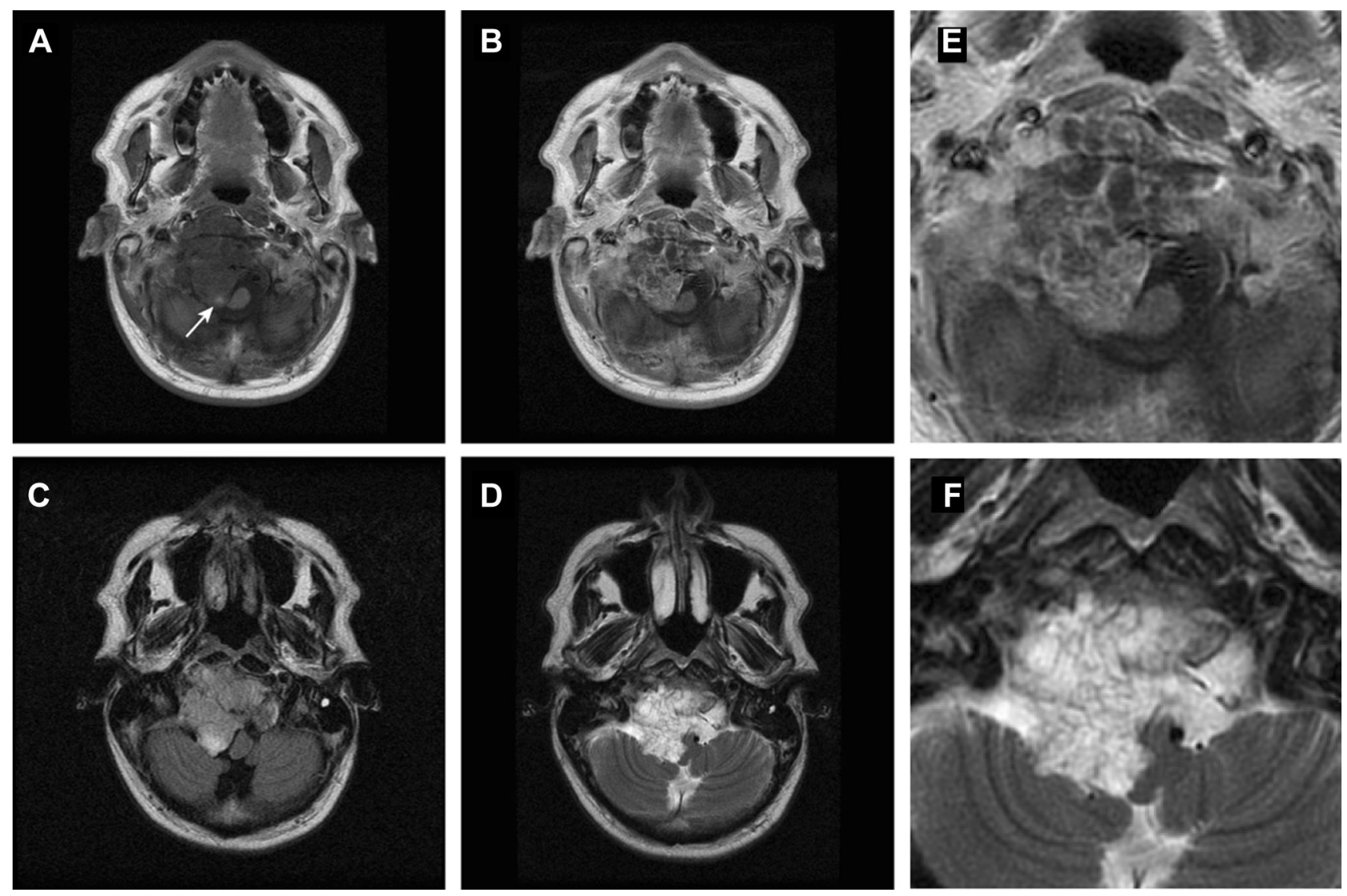

Fig. 2 Chordoma. Magnetic resonance imaging of a skull base chordoma arising at the clivus with compression of the brain stem. Axial T1-weighted imaging (a) shows a mass with mostly hypointense signal, a hyperintense focus (arrow) and heterogeneous

diagnosing chordoma metastasis remains questionable as prognosis is more related to local disease at primary site than metastasis $[53,54]$.

\section{Role of Nuclear Medicine}

The role of molecular imaging in diagnosis or treatment of chordoma is scarcely explored. Mirra et al. [58] described no abnormalities of chordoma on bone scans. To our knowledge, there are no studies of other PET tracers of skull base chordoma. Few studies have been performed in PET tracers of mobile spine and sacral chordoma. As skull base chordoma have similar molecular expression [35] as mobile spine and sacral chordoma, these tumours may be considered the same entity. Case reports show a heterogenous moderate pathological uptake of fluorodeoxyglucose $\left({ }^{18} \mathrm{~F}\right.$-FDG) uptake (SUVmax 4.5) within the primary tumour mass of a sacrococcygeal chordoma $[59,60]$. These studies suggest that FDG-PET may aid in the diagnosis of chordoma metastasis. A recent study [61] showed ${ }^{18} \mathrm{~F}$-FDG uptake in chordoma metastases, as well contrast uptake (b, e). Axial FLAIR (c) shows heterogenous tumour intensity. T2-weighted imaging (c, f) shows mostly hyperintense signal intensity with linear foci of hypointensity. Pathologic examination confirmed the diagnosis of chordoma

as ${ }^{68}$ GA-DOTA-TATE uptake in one chordoma with metastases. As stated earlier, the clinical relevance of diagnosing metastases is questionable as prognosis is more related to local disease control than metastasis [53, 54]. Nonetheless, ${ }^{18}$ F-FDG-PET is used in the follow-up of chemotherapy studies in chordoma, and may become an important aspect in future follow-up of chordoma patients [62].

Fluoromisonidazole positron emission tomography (FMISO-PET) is used in delineating areas of hypoxia in tumours [63]. Hypoxic areas in tumours are generally difficult to treat, as these areas are generally radioresistant and show increased resistance to cytotoxic chemotherapy [64]. The knowledge of hypoxic areas can be used in radiotherapy dose painting with boost volumes on these hypoxic areas. The feasibility of FMISO-PET-CT-guided radiotherapy with hypoxia-directed intensity modulated radiotherapy has been demonstrated in multiple tumours $[63,65,66]$, including head and neck cancer [67]. Cheney et al. [68] showed that hypoxic areas could be identified with FMISO-PET-CT in 12 out of 20 chordoma of the mobile or sacrococcygeal spine. The benefits and risks of 
hypoxia-guided boost volumes in radiotherapy of chordoma still have to be investigated in the future.

\section{Differential Diagnosis}

As stated earlier, chordoma are assumed to arise from remnants of the foetal notochord. The notochord is a rodshaped embryologic structure that develops in the third week of gestation, and serves as an molecular inducer for vertebral column formation [69]. As the vertebral column develops, the notochord degrades into clusters in what later becomes the nucleus pulposus [70]. Notochordal cells are normally found in the intervertebral disc in the postnatal period until the early adult life [71]. However, embryological studies of human foetuses have demonstrated ectopic notochordal remnants along the axial skeleton, and especially at the caudal and cranial ends [72]. It is thought that these notochordal remnants may proliferate into chordoma. Over the years, multiple benign tumours with notochordal cell origin have also been described, i.e. ecchordosis physaliphora [73], giant notochordal rest [74-76], giant notochordal hamartoma [58] and are now usually categorized in the comprehensive term 'benign notochordal cell tumours'. These tumours are thought to be proliferated remnants of the notochord, with a benign character [58, 77]. It is debated whether a BNCT may undergo malignant transformation to chordoma [78-81]. In autopsy studies performed by Yamaguchi et al. [80], 20\% of the cadavers showed foci of BNCT in the axial skeleton. It should be emphasized that $>50 \%$ of these foci were $<2 \mathrm{~mm}$ in size and are probably not seen in imaging. Benign notochordal cell tumours and chordoma differ in radiologic and histologic features. On computed tomography, BNCTs are usually occult or show slight sclerosis without bone destruction [82]. On MRI, BNCTs show low $\mathrm{T} 1$ signal intensity and intermediate-to-high signal intensity on T2-weighted images and are almost exclusively intraosseous without soft tissue extension or contrast enhancement [83, 84]. Figure 3 shows an intraosseous lesion with the imaging characteristics of a BNCT. Multiple studies suggest imaging follow-up when a lesion is suspect of BNCT [1, 82]. However, because of the huge difference in the prevalence of BNCT and incidence of chordoma (20\% versus $0.08 / 100,000$ per year), follow-up imaging may only be necessary if the lesion shows atypical BNCT imaging characteristics, like bone destruction. However, there are no long-term studies in follow-up of BNCT.

Of all benign notochordal cell lesions, ecchordosis physaliphora (EP) are a subtype that was already described in the 19th century. EP are described as a congenital, benign, gelatinous tissue that is considered an ectopic notochordal remnant [85]. Ecchordosis physaliphora are found in around 2\% of autopsy studies [73] and approximately $1.7 \%$ in MRI studies [85, 86]. Even though this lesion appears to be common, it is easily overlooked. Typically, EP are small, well-circumscribed, extra-axial, intradural lesions in the prepontine cistern, which have a predilection for the midline posterior clivus at the level of Dorello's canal $[85,87,88]$. On MRI, EP show high signal intensity on $\mathrm{T} 2$-weighted images and low signal intensity on T1-weighted images, similar to chordoma, but do not show contrast enhancement [85, 86, 88-92]. Differentiating EP from intradural chordoma is essential, as EP are benign and usually asymptomatic and therefore do not need treatment [93].

Chondrosarcoma are the most difficult differential diagnosis of chordoma of the skull base, as these lesions have overlapping radiologic and histopathologic features [52]. Many previous studies have found no definite CT or MRI features that distinguish between chordoma and chondrosarcoma [38, 47, 52]. However, there are some features that favour one over the other. Chordoma typically originate in the clivus and are therefore generally located more centrally, whereas chondrosarcoma arise in the petroclival fissure and therefore occur more laterally. [38] Unfortunately, this is not a distinctive feature, as lateral skull base chordoma have also been described [94, 95]. On CT, chondrosarcoma may show a typical 'ring-and-arc' chondroid matrix mineralization [96]. Figure 4 shows typical imaging characteristics of a chondrosarcoma. Recent studies show that diffusion-weighted imaging may differentiate between chordoma and chondrosarcoma, with chondrosarcoma having a higher average apparent diffusion coefficient than chordoma [51•, 97, 98]. The use of DWI in chordoma imaging is further elaborated below in 'prognostics and radiomics'.

Table 1 gives an overview of the typical imaging characteristics of chordoma, BNCT and chondrosarcoma.

\section{Post-treatment Evaluation}

As chordoma show high recurrent rates [7], follow-up seems obvious. However, there is no evidence for any type of follow-up in chordoma. Stacchiotti et al. [99], on behalf of 'the chordoma global consensus group', proposed follow-up imaging of the primary tumour site with MRI during the first 4-5 years after diagnosis every 6 months. Thereafter, if no disease progression is observed, MRI should be done every year for at least 15 years. There was no consensus about follow-up of metastasis in this group. Guler et al. [100] studied the follow-up of chordoma using MRI with incorporating DWI and concluded that the 

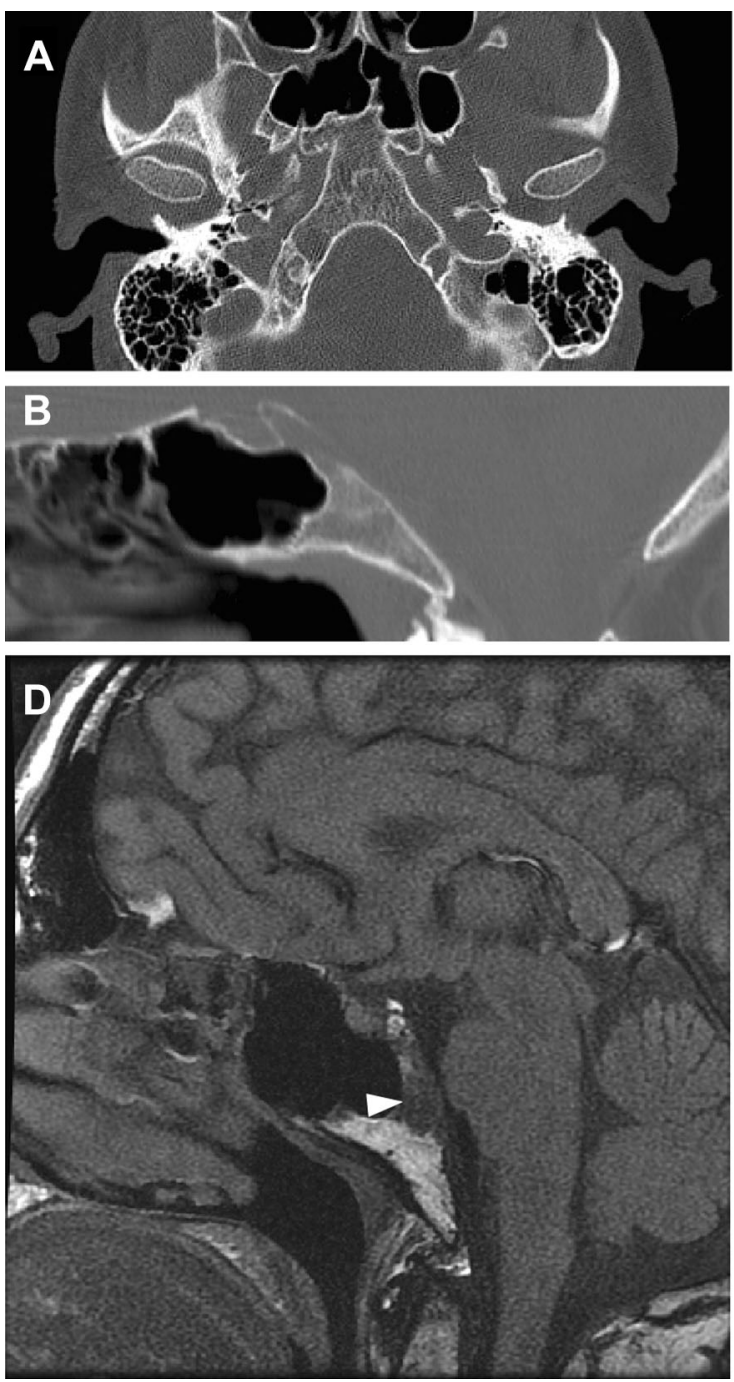

Fig. 3 BNCT. Imaging of a well-defined intraosseous lesion in the base of the skull. CT imaging of the clivus in axial (a) and sagittal (b) plane shows normal bone trabeculation. There is no trabecular or cortical destruction. T2-weighted MRI imaging in axial plane (c) shows a hyperintense mass at the clivus, which is hypointense on T1-weighted imaging (arrow, d) and does not show contrast

detectability of residual chordoma tumour tissue on DWI is better than T2 or FLAIR sequences.

\section{Prognostics and Radiomics}

As stated earlier, chordoma have a high recurrence rate, with up to $20 \%$ recurrence in the first year after diagnoses [7]. Unfortunately, prognostic factors in chordoma are largely unknown. Histopathologic studies have shown that poor differentiation type, high mitotic activity, prominent nucleoli, high Ki67 and high p53-LI significantly correlates with poor progression-free survival [101]. The presence of necrosis and apoptosis is related to poor overall survival
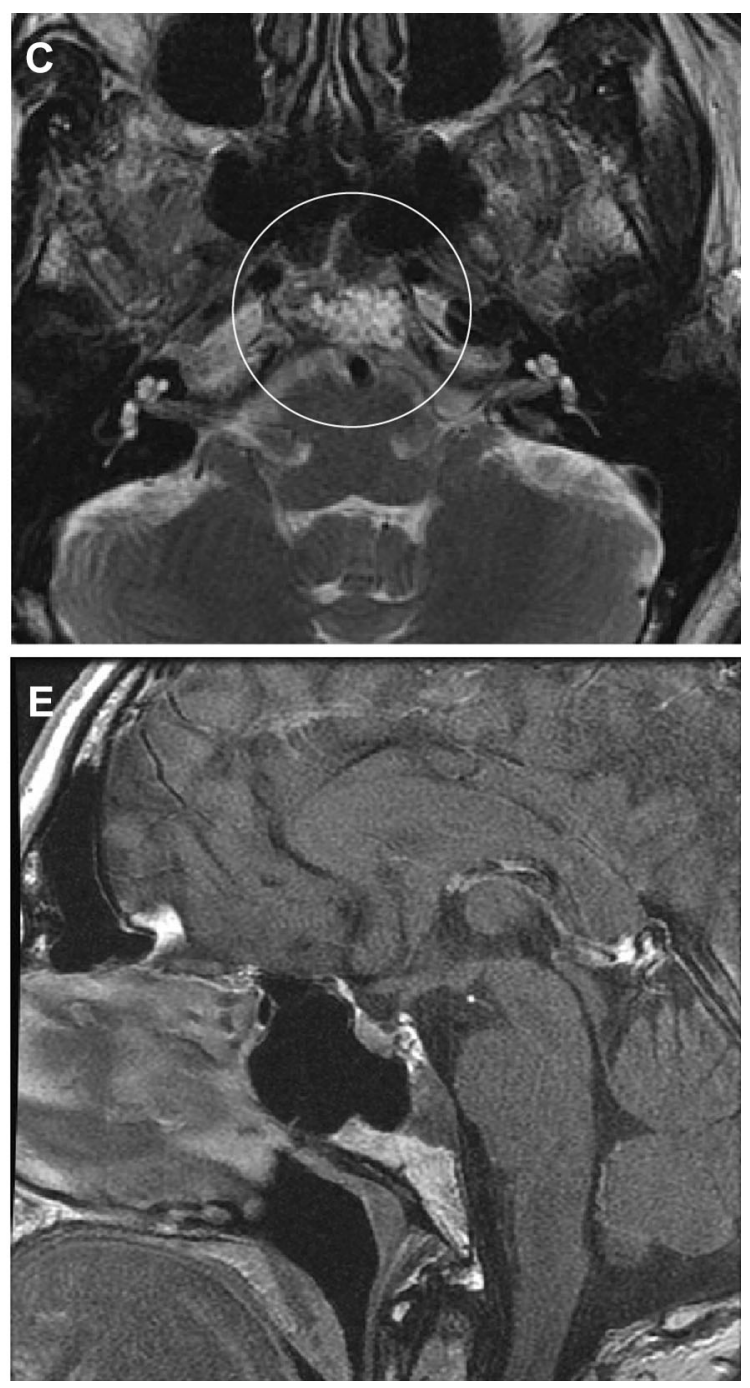

enhancement (e), as opposed to the physiological contrast enhancement of the pituitary gland. This tumour shows typical imaging characteristics of a benign notochordal cell tumour. However, there was no pathologic confirmation. On follow-up MRI after 1 year, the lesion was unchanged

[101]. Moreover, better overall survival is linked to the possibility of high resection rate and smaller tumour size [4]. Skull base chordoma show a better overall survival than sacral chordoma, most likely due to the smaller average sizes in skull base chordoma, as tumours in this location become symptomatic sooner and therefore detected at an earlier stage [4].

Little is known about prognostic imaging characteristics in chordoma. Large radiomics studies have not yet been performed. A few pilot studies have been conducted in chordoma imaging characteristics for prognostic and differential diagnostic purposes. A recent study performed by Tian et al. [102••] studied the tumour-to-pons signal intensity ratios of 156 patients with skull base chordoma and showed 

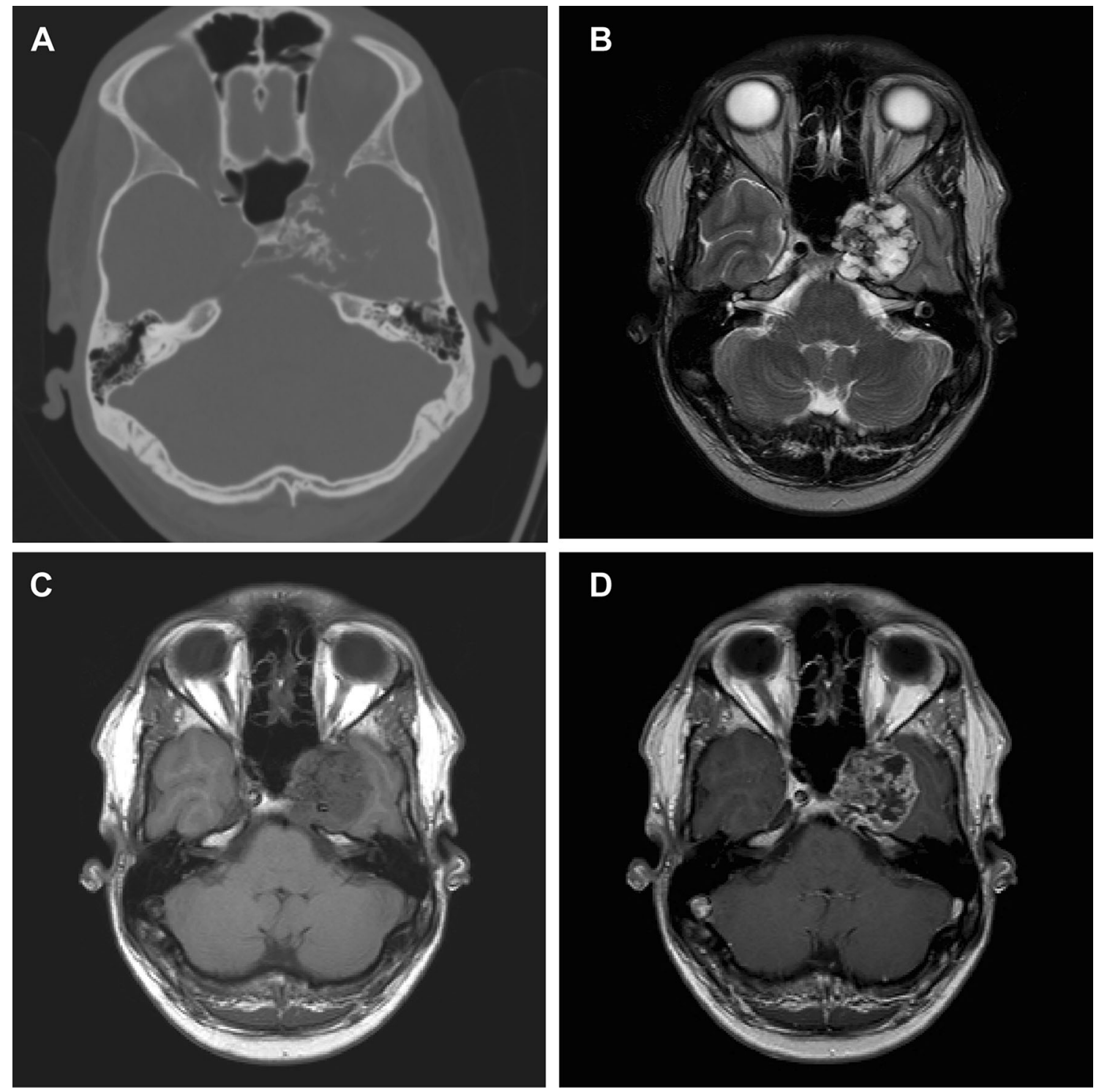

Fig. 4 Chondrosarcoma. Imaging of skull base chondrosarcoma arising from the left lateral clivus with extension to the clinoid process, cavernous sinus and intracranial extension and compression on the left temporal lobe. Computed tomography (a) shows bone destruction with hyperdense fragments in the tumour mass, which corresponds with the typical 'rings-and-arcs' seen in chondroid

tumours like chondrosarcoma. T2-weighted imaging (b) shows a heterogenous, mostly hyperintense mass. T1-weighted imaging (c) shows a hypointense mass with heterogenous enhancement (d). Pathologic examination of the tumour mass concluded chondrosarcoma WHO grade 1

Table 1 Imaging characteristics of chordoma and differential diagnosis

\begin{tabular}{llllll}
\hline & T1 & T2 & Contrast enhancement & Bone destruction & Preferred location \\
\hline Chordoma & Low to intermediate & High & Yes & Yes & Midline \\
Chondrosarcoma & Low to intermediate & High & Yes & Yes & Out of midline \\
BNCT & Low & High & No & No & Intraosseous, no soft tissue extension \\
EP & High & No & No & Midline. Stalk with clivus. Extraosseous \\
\hline
\end{tabular}

that a higher $\mathrm{T} 2$ signal ratio (tumour: pons) was an indicator of slow tumour progression, whereas a high enhanced $\mathrm{T} 1$ FLAIR ratio (tumour: pons) was a positive indicator of tumour progression. Low T2 signal intensity and high T1 contrast-enhanced signal intensity may be associated with abundant blood supply of the tumour. These ratios used in 
this study were also categorized in a gradient system which showed increased tumour progression with higher grade. Future prospective studies are needed to evaluate the efficacy of this grading system.

Diffusion-weighted imaging (DWI) is an unenhanced MRI technique based on the restriction of Brownian motion of extracellular water [103]. The apparent diffusion coefficient (ADC) is a quantitative measure of this movement. This difference can also aid in the characterization of tumorous tissue, as water molecule diffusion is reflective of tissue organizational features, i.e. cellularity, nuclear-tocytoplasmic ratio and reduced extracellular matrix $[104,105]$. It is believed that benign tumours have lower cellularity, whereas malignant tumours generally show high cellularity with high mitotic activity [106]. Studies show that quantitative DWI with ADC mapping can distinguish between benign and malignant musculoskeletal lesions of the skull [104, 105]. The myxoid stroma of chordomas, with nests of physaliphorous cells separated with fibrous strands may impede extracellular water motion [51•]. As stated earlier, DWI with quantitative ADC mapping may be used in differentiating chordoma from chondrosarcoma, with chondrosarcoma having a higher average ADC value than chordoma [51•,97, 98]. The mean value in a study of Yeom et al. [51•] was $2051 \pm 261 \times 10^{-6} \mathrm{~mm}^{2} / \mathrm{s}$ for chondrosarcoma, followed by $1474 \pm 117 \times 10^{-6}$ Ecchordosis physaliphora $\mathrm{mm}^{2} / \mathrm{s}$ for classic chordoma and $875 \pm 100 \times 10^{-6} \mathrm{~mm}^{2} / \mathrm{s}$ for poorly differentiated chordoma. This is in accordance with the premise that malignant tumours have higher cellularity and therefore lower ADC values. More research is needed to evaluate relationship of ADC values and prognosis in patients with chordoma.

A recent study by Lang et al. [107] used dynamic contrast-enhanced (DCE) MRI to differentiate chordoma from giant cell tumours of the skull base. Dynamic contrast enhancement is an MRI technique which calculates the perfusion of tissue [108]. A typical DCE kinetic pattern was described for chordoma which was significantly different from giant cell tumours. In this study, chordoma show typical quick enhancement without washout, as opposed to giant cell tumours, which show quick enhancement and washout. To our knowledge, there are no studies that evaluate the role of DCE-MRI in the differentiation of chordoma and other lesions of the skull base.

\section{Future Directions in Chordoma Imaging}

The imaging characteristics of chordoma with CT and standard MRI sequences are well described in the late 1980s and early 1990s [46-50]. At that time, imaging was used for diagnostic and treatment planning purposes. The first molecular PET studies were performed halfway the 2000s. Molecular imaging data of chordoma with PET-CT are currently still limited but may become important in the future. The driving mechanisms behind chordoma are still largely unknown. Imaging may become more important in differentiating between slow-growing and fast-growing lesions, and therefore crucial in treatment planning. The presence of hypoxic areas in chordoma, which has been confirmed by FMISO-uptake [68], may be an indicator of poor prognosis. More research is needed to evaluate the role of hypoxia in the prognosis of chordoma and the benefit of hypoxia-adjusted radiotherapy.

Targeted radionuclide therapy (TRT) is a hot topic in cancer therapy nowadays. Coupling radionuclides to tumour-specific targeting agents, i.e. tumour-specific membrane receptors, delivers radiation to the cancer cells that express these membrane receptors. The discovery of ${ }^{68} \mathrm{GA}$-DOTA-TATE uptake in chordoma is exciting. ${ }^{68} \mathrm{GA}$ DOTA-TATE is a somatostatin receptor analogue, and ${ }^{68}$ GA-DOTA-TATE PET-CT plays an important role in the detection of primary tumour, metastases, staging, restaging and assessment of treatment response in patients with neuroendocrine tumours [109]. Studies show that ${ }^{68} \mathrm{GA}$ DOTA-TATE uptake in neuroendocrine tumours also predicts response to somatostatin receptor-mediated radionuclide therapy $[110,111]$. More research is needed to evaluate the role of ${ }^{68} \mathrm{GA}$-DOTA-TATE in larger chordoma cohorts and the efficacy of treatment using somatostatin receptor-mediated radionuclides in chordoma.

To our knowledge, no studies have been performed to evaluate the use of PET-MR in chordoma. The high spatial resolution of MR combined with the molecular and functional information of PET may aid in diagnosis and surgery strategy planning. Further advancements in molecular imaging may aid in the differential diagnosis of skull base lesions. Radiolabelled molecular probes may be used to identify unique proteins in cancer cells [112], or even used as biomarkers. Molecular imaging by PET may function as a bridge between in vitro and in vivo biology of disease.

Imaging research is focussing more and more on the new emerging and rapidly evolving field of radiomics. Advanced imaging characteristics may become a key player in predicting cancer aggressiveness, or prediction of response or resistance to treatment [113]. This is already used in diagnosis, treatment planning and disease monitoring of brain tumours [114]. Radiomics is a field of imaging studies which uses quantitative imaging features, like signal intensity, size, shape and texture for information on tumour phenotype and microenvironment [115]. Assessing these imaging features and linking these to prognostic data may lead to calculation of individualized prognosis and tailor-made personalized treatment. Pilot studies in radiomics have been performed, but large studies 
are still missing. New state-of-the-art MRI tools, like DWI, spectroscopy, dynamic contrast-enhanced MRI and BOLD have barely been studied. Future studies are needed to evaluate the role of these techniques in diagnosis, treatment and follow-up of chordoma. Despite a large imaging arsenal, diagnosis and treatment response largely depend on semantic features based on conventional imaging. Advanced, hybrid techniques and quantitative measures are being implemented more and more and in the future can aid in increased personalized medicine.

\section{Compliance with Ethical Guidelines}

Conflict of interest Rene G.C. Santegoeds, Yasin Temel, Jan C. Beckervordersandforth, Jacobus J. Van Overbeeke and Christianne M. Hoeberigs each declare no potential conflicts of interest.

Human and Animal Rights and Informed Consent This article does not contain any studies with human or animal subjects performed by any of the authors.

Open Access This article is distributed under the terms of the Creative Commons Attribution 4.0 International License (http:// creativecommons.org/licenses/by/4.0/), which permits unrestricted use, distribution, and reproduction in any medium, provided you give appropriate credit to the original author(s) and the source, provide a link to the Creative Commons license, and indicate if changes were made.

\section{References}

Recently published papers of particular interest have been highlighted as:

- Of importance

•. Of major importance

1. Kyriakos M. Benign notochordal lesions of the axial skeleton: a review and current appraisal. Skelet Radiol. 2011;40(9):1141-52.

2. Yakkioui Y, van Overbeeke JJ, Santegoeds R, van Engeland M, Temel Y. Chordoma: the entity. Biochim Biophys Acta. 2014;1846(2):655-69.

3. McMaster ML, Goldstein AM, Bromley CM, Ishibe N, Parry DM. Chordoma: incidence and survival patterns in the United States, 1973-1995. Cancer Causes Control. 2001;12(1):1-11.

4. Lee IJ, Lee RJ, Fahim DK. Prognostic factors and survival outcome in patients with chordoma in the United States: a population-based analysis. World Neurosurg. 2017;104:346-55.

5. Whelan J, McTiernan A, Cooper N, Wong YK, Francis M, Vernon S, et al. Incidence and survival of malignant bone sarcomas in England 1979-2007. Int J Cancer. 2012;131(4):E508-17.

6. Jones PS, Aghi MK, Muzikansky A, Shih HA, Barker FG 2nd, Curry WT Jr. Outcomes and patterns of care in adult skull base chordomas from the Surveillance, Epidemiology, and End Results (SEER) database. J Clin Neurosci. 2014;21(9):1490-6.

7. Wu Z, Zhang J, Zhang L, Jia G, Tang J, Wang L, et al. Prognostic factors for long-term outcome of patients with surgical resection of skull base chordomas-106 cases review in one institution. Neurosurg Rev. 2010;33(4):451-6.

8. Walcott BP, Nahed BV, Mohyeldin A, Coumans JV, Kahle KT, Ferreira MJ. Chordoma: current concepts, management, and future directions. Lancet Oncol. 2012;13(2):e69-76.

9. Stacchiotti S, Gronchi A, Fossati P, Akiyama T, Alapetite C, Baumann M, et al. Best practices for the management of localregional recurrent chordoma: a position paper by the Chordoma Global Consensus Group. Ann Oncol. 2017;28(6):1230-42.

10. Rich TA, Schiller A, Suit HD, Mankin HJ. Clinical and pathologic review of 48 cases of chordoma. Cancer. 1985;56(1):182-7.

11. Sundaresan N, Galicich JH, Chu FC, Huvos AG. Spinal chordomas. J Neurosurg. 1979;50(3):312-9.

12. Bjornsson J, Wold LE, Ebersold MJ, Laws ER. Chordoma of the mobile spine. A clinicopathologic analysis of 40 patients. Cancer. 1993;71(3):735-40.

13. Doucet V, Peretti-Viton P, Figarella-Branger D, Manera L, Salamon G. MRI of intracranial chordomas. Extent of tumour and contrast enhancement: criteria for differential diagnosis. Neuroradiology. 1997;39(8):571-6.

14. Chugh R, Tawbi H, Lucas DR, Biermann JS, Schuetze SM, Baker LH. Chordoma: the nonsarcoma primary bone tumor. Oncologist. 2007;12(11):1344-50.

15. Tomlinson FH, Scheithauer BW, Forsythe PA, Unni KK, Meyer FB. Sarcomatous transformation in cranial chordoma. Neurosurgery. 1992;31(1):13-8.

16. Barnes L, Kapadia SB. The biology and pathology of selected skull base tumors. J Neurooncol. 1994;20(3):213-40.

17. Hoch BL, Nielsen GP, Liebsch NJ, Rosenberg AE. Base of skull chordomas in children and adolescents: a clinicopathologic study of 73 cases. Am J Surg Pathol. 2006;30(7):811-8.

18. Mobley BC, McKenney JK, Bangs CD, Callahan K, Yeom KW, Schneppenheim R, et al. Loss of SMARCB1/INI1 expression in poorly differentiated chordomas. Acta Neuropathol. 2010;120(6):745-53.

19. Borba LA, Al-Mefty O, Mrak RE, Suen J. Cranial chordomas in children and adolescents. J Neurosurg. 1996;84(4):584-91.

20. Kim SC, Cho W, Chang UK, Youn SM. Two cases of dedifferentiated chordoma in the sacrum. Korean $\mathrm{J}$ Spine. 2015;12(3):230-4.

21. Frankl J, Grotepas C, Stea B, Lemole GM, Chiu A, Khan R. Chordoma dedifferentiation after proton beam therapy: a case report and review of the literature. J Med Case Rep. 2016;10(1):280.

22. Heffelfinger MJ, Dahlin DC, MacCarty CS, Beabout JW. Chordomas and cartilaginous tumors at the skull base. Cancer. 1973;32(2):410-20.

23. Forsyth PA, Cascino TL, Shaw EG, Scheithauer BW, O'Fallon JR, Dozier JC, et al. Intracranial chordomas: a clinicopathological and prognostic study of 51 cases. J Neurosurg. 1993;78(5):741-7.

24. Bottles K, Beckstead JH. Enzyme histochemical characterization of chordomas. Am J Surg Pathol. 1984;8(6):443-7.

25. Brooks JJ, LiVolsi VA, Trojanowski JQ. Does chondroid chordoma exist? Acta Neuropathol. 1987;72(3):229-35.

26. Ishida T, Dorfman HD. Chondroid chordoma versus low-grade chondrosarcoma of the base of the skull: can immunohistochemistry resolve the controversy? J Neurooncol. 1994;18(3):199-206.

27. Rosenberg AE, Brown GA, Bhan AK, Lee JM. Chondroid chordoma-a variant of chordoma. A morphologic and immunohistochemical study. Am J Clin Pathol. 1994;101(1):36-41. 
28. Walker WP, Landas SK, Bromley CM, Sturm MT. Immunohistochemical distinction of classic and chondroid chordomas. Mod Pathol. 1991;4(5):661-6.

29. Almefty K, Pravdenkova S, Colli BO, Al-Mefty O, Gokden M. Chordoma and chondrosarcoma: similar, but quite different, skull base tumors. Cancer. 2007;110(11):2457-67.

30. Cho YH, Kim JH, Khang SK, Lee JK, Kim CJ. Chordomas and chondrosarcomas of the skull base: comparative analysis of clinical results in 30 patients. Neurosurg Rev. 2008;31(1):35-43 discussion 43

31. Murad TM, Murthy MS. Ultrastructure of a chordoma. Cancer. 1970;25(5):1204-15.

32. Erlandson RA, Tandler B, Lieberman PH, Higinbotham NL. Ultrastructure of human chordoma. Cancer Res. 1968;28(10):2115-25.

33. El-Heliebi A, Kroneis T, Wagner K, Meditz K, Kolb D, Feichtinger $\mathrm{J}$, et al. Resolving tumor heterogeneity: genes involved in chordoma cell development identified by low-template analysis of morphologically distinct cells. PLoS ONE. 2014;9(2):e87663.

34. Pena CE, Horvat BL, Fisher ER. The ultrastructure of chordoma. Am J Clin Pathol. 1970;53(4):544-51.

35. Vujovic S, Henderson S, Presneau N, Odell E, Jacques TS, Tirabosco R, et al. Brachyury, a crucial regulator of notochordal development, is a novel biomarker for chordomas. J Pathol. 2006;209(2):157-65.

36. Oakley GJ, Fuhrer K, Seethala RR. Brachyury, SOX-9, and podoplanin, new markers in the skull base chordoma vs chondrosarcoma differential: a tissue microarray-based comparative analysis. Mod Pathol. 2008;21(12):1461-9.

37. Van Gompel JJ, Janus JR. Chordoma and chondrosarcoma. Otolaryngol Clin N Am. 2015;48(3):501-14.

38. Weber AL, Liebsch NJ, Sanchez R, Sweriduk ST Jr. Chordomas of the skull base. Radiologic and clinical evaluation. Neuroimaging Clin N Am. 1994;4(3):515-27.

39. Azzopardi C, Grech R, Mizzi A. Teaching NeuroImages: chordoma. Neurology. 2014;83(10):e110-1.

40. Goodarzi A, Toussi A, Lechpammer M, Lee D, Shahlaie K. Intradural chordoma of the cerebellopontine angle: case report and review. World Neurosurg. 2017. https://doi.org/10.1016/j. wneu.2017.08.124.

41. Katayama Y, Tsubokawa T, Hirasawa T, Takahata T, Nemoto $\mathrm{N}$. Intradural extraosseous chordoma in the foramen magnum region. Case report. J Neurosurg. 1991;75(6):976-9.

42. Meyer JE, Oot RF, Lindfors KK. CT appearance of clival chordomas. J Comput Assist Tomogr. 1986;10(1):34-8.

43. Brown RV, Sage MR, Brophy BP. CT and MR findings in patients with chordomas of the petrous apex. AJNR Am J Neuroradiol. 1990;11(1):121-4.

44. Erdem E, Angtuaco EC, Van Hemert R, Park JS, Al-Mefty O. Comprehensive review of intracranial chordoma. Radiographics. 2003;23(4):995-1009.

45. Meyer JE, Lepke RA, Lindfors KK, Pagani JJ, Hirschy JC, Hayman LA, et al. Chordomas: their CT appearance in the cervical, thoracic and lumbar spine. Radiology. 1984;153(3):693-6.

46. Meyers SP, Hirsch WL Jr, Curtin HD, Barnes L, Sekhar LN, Sen C. Chordomas of the skull base: MR features. AJNR Am J Neuroradiol. 1992;13(6):1627-36.

47. Oot RF, Melville GE, New PF, Austin-Seymour M, Munzenrider J, Pile-Spellman J, et al. The role of MR and CT in evaluating clival chordomas and chondrosarcomas. AJR Am J Roentgenol. 1988;151(3):567-75.

48. Leproux F, de Toffol B, Aesch B, Cotty P. MRI of cranial chordomas: the value of gadolinium. Neuroradiology. 1993;35(7):543-5.
49. Tashiro T, Inoue Y, Nemoto Y, Shakudo M, Mochizuki K, Yahata $\mathrm{S}$, et al. Magnetic resonance (MR) imaging of chordoma and chondroma in the skull base-differential diagnosis by IR sequence. Nihon Igaku Hoshasen Gakkai Zasshi. 1992;52(5):589-93.

50. Sze G, Uichanco LS 3rd, Brant-Zawadzki MN, Davis RL, Gutin $\mathrm{PH}$, Wilson $\mathrm{CB}$, et al. Chordomas: MR imaging. Radiology. 1988;166(1 Pt 1):187-91.

51. •Yeom KW, Lober RM, Mobley BC, Harsh G, Vogel H, Allagio $\mathrm{R}$, et al. Diffusion-weighted MRI: distinction of skull base chordoma from chondrosarcoma. AJNR Am J Neuroradiol. 2013;34(5):1056-61, S1. This article describes the use of DWI in differentiation clival tumour, which may become a routinely used MRI sequence in chordoma imaging and possibly.

52. Pamir MN, Ozduman K. Analysis of radiological features relative to histopathology in 42 skull-base chordomas and chondrosarcomas. Eur J Radiol. 2006;58(3):461-70.

53. Stacchiotti S, Casali PG, Lo Vullo S, Mariani L, Palassini E, Mercuri M, et al. Chordoma of the mobile spine and sacrum: a retrospective analysis of a series of patients surgically treated at two referral centers. Ann Surg Oncol. 2010;17(1):211-9.

54. Kishimoto R, Omatsu T, Hasegawa A, Imai R, Kandatsu S, Kamada T. Imaging characteristics of metastatic chordoma. Jpn J Radiol. 2012;30(6):509-16.

55. Chambers PW, Schwinn CP. Chordoma. A clinicopathologic study of metastasis. Am J Clin Pathol. 1979;72(5):765-76.

56. Fagundes MA, Hug EB, Liebsch NJ, Daly W, Efird J, Munzenrider JE. Radiation therapy for chordomas of the base of skull and cervical spine: patterns of failure and outcome after relapse. Int J Radiat Oncol Biol Phys. 1995;33(3):579-84.

57. McPherson CM, Suki D, McCutcheon IE, Gokaslan ZL, Rhines LD, Mendel E. Metastatic disease from spinal chordoma: a 10-year experience. J Neurosurg Spine. 2006;5(4):277-80.

58. Mirra JM, Brien EW. Giant notochordal hamartoma of intraosseous origin: a newly reported benign entity to be distinguished from chordoma. Report of two cases. Skelet Radiol. 2001;30(12):698-709.

59. Park SA, Kim HS. F-18 FDG PET/CT evaluation of sacrococcygeal chordoma. Clin Nucl Med. 2008;33(12):906-8.

60. Ochoa-Figueroa MA, Martinez-Gimeno E, Allende-Riera A, Cabello-Garcia D, Munoz-Iglesias J, Cardenas-Negro C. Role of 18F-FDG PET-CT in the study of sacrococcygeal chordoma. Rev Esp Med Nucl Imagen Mol. 2012;31(6):359-61.

61. Derlin T, Sohns JM, Hueper K. 68 Ga-DOTA-TATE PET/CT for molecular imaging of somatostatin receptor expression in metastasizing chordoma: comparison with 18F-FDG. Clin Nucl Med. 2017;42(4):e210-1.

62. Stacchiotti S, Longhi A, Ferraresi V, Grignani G, Comandone A, Stupp R, et al. Phase II study of imatinib in advanced chordoma. J Clin Oncol. 2012;30(9):914-20.

63. Qiu J, Lv B, Fu M, Wang X, Zheng X, Zhuo W. 18 F-Fluoromisonidazole positron emission tomography/CT-guided volumetric-modulated arc therapy-based dose escalation for hypoxic subvolume in nasopharyngeal carcinomas: a feasibility study. Head Neck. 2017;39(12):2519-27.

64. Padhani AR, Krohn KA, Lewis JS, Alber M. Imaging oxygenation of human tumours. Eur Radiol. 2007;17(4):861-72.

65. Sato J, Kitagawa Y, Watanabe S, Asaka T, Ohga N, Hirata K, et al. 18F-Fluoromisonidazole positron emission tomography (FMISO-PET) may reflect hypoxia and cell proliferation activity in oral squamous cell carcinoma. Oral Surg Oral Med Oral Pathol Oral Radiol. 2017;124(3):261-70.

66. Lindblom E, Dasu A, Uhrdin J, Even A, van Elmpt W, Lambin $\mathrm{P}$, et al. Defining the hypoxic target volume based on positron emission tomography for image guided radiotherapy-the 
influence of the choice of the reference region and conversion function. Acta Oncol. 2017;56(6):819-25.

67. Lee NY, Mechalakos JG, Nehmeh S, Lin Z, Squire OD, Cai S, et al. Fluorine-18-labeled fluoromisonidazole positron emission and computed tomography-guided intensity-modulated radiotherapy for head and neck cancer: a feasibility study. Int J Radiat Oncol Biol Phys. 2008;70(1):2-13.

68. Cheney MD, Chen YL, Lim R, Winrich BK, Grosu AL, Trofimov AV, et al. [18F]-Fluoromisonidazole positron emission tomography/computed tomography visualization of tumor hypoxia in patients with chordoma of the mobile and sacrococcygeal spine. Int $\mathrm{J}$ Radiat Oncol Biol Phys. 2014;90(5):1030-6.

69. Ramesh T, Nagula SV, Tardieu GG, Saker E, Shoja M, Loukas $\mathrm{M}$, et al. Update on the notochord including its embryology, molecular development, and pathology: a primer for the clinician. Cureus. 2017;9(4):e1137.

70. Choi KS, Cohn MJ, Harfe BD. Identification of nucleus pulposus precursor cells and notochordal remnants in the mouse: implications for disk degeneration and chordoma formation. Dev Dyn. 2008;237(12):3953-8.

71. Weiler C, Nerlich AG, Schaaf R, Bachmeier BE, Wuertz K, Boos N. Immunohistochemical identification of notochordal markers in cells in the aging human lumbar intervertebral disc. Eur Spine J. 2010;19(10):1761-70.

72. Horwitz T. The human notochord: a study of its development and regression, variations, and pathologic derivative, chordoma. Syndey: Horwitz; 1977.

73. Stewart MJ, Burrow Jle F. Ecchordosis physaliphora sphenooccipitalis. J Neurol Psychopathol. 1923;4(15):218-20.

74. Oner AY, Akpek S, Tali T, Ucar M. Giant vertebral notochordal rest: magnetic resonance and diffusion weighted imaging findings. Korean J Radiol. 2009;10(3):303-6.

75. Chauvel A, Taillat F, Gille O, Rivel J, Vital JM, Bioulac-Sage P, et al. Giant vertebral notochordal rest: a new entity distinct from chordoma. Histopathology. 2005;47(6):646-9.

76. Kyriakos M, Totty WG, Lenke LG. Giant vertebral notochordal rest: a lesion distinct from chordoma: discussion of an evolving concept. Am J Surg Pathol. 2003;27(3):396-406.

77. Golden LD, Small JE. Benign notochordal lesions of the posterior clivus: retrospective review of prevalence and imaging characteristics. J Neuroimaging. 2014;24(3):245-9.

78. Yamaguchi T, Suzuki S, Ishiiwa H, Ueda Y. Intraosseous benign notochordal cell tumours: overlooked precursors of classic chordomas? Histopathology. 2004;44(6):597-602.

79. Yamaguchi T, Yamato M, Saotome K. First histologically confirmed case of a classic chordoma arising in a precursor benign notochordal lesion: differential diagnosis of benign and malignant notochordal lesions. Skelet Radiol. 2002;31(7):413-8.

80. Yamaguchi T, Suzuki S, Ishiiwa H, Shimizu K, Ueda Y. Benign notochordal cell tumors: a comparative histological study of benign notochordal cell tumors, classic chordomas, and notochordal vestiges of fetal intervertebral discs. Am J Surg Pathol. 2004;28(6):756-61.

81. Deshpande V, Nielsen GP, Rosenthal DI, Rosenberg AE. Intraosseous benign notochord cell tumors (BNCT): further evidence supporting a relationship to chordoma. Am J Surg Pathol. 2007;31(10):1573-7.

82. Carter JM, Wenger DE, Rose PS, Inwards CY. Atypical notochordal cell tumors: a series of notochordal-derived tumors that defy current classification schemes. Am J Surg Pathol. 2017;41(1):39-48.

83. Yamaguchi T, Iwata J, Sugihara S, McCarthy EF Jr, Karita M, Murakami $\mathrm{H}$, et al. Distinguishing benign notochordal cell tumors from vertebral chordoma. Skelet Radiol. 2008;37(4):291-9.
84. Nishiguchi T, Mochizuki K, Ohsawa M, Inoue T, Kageyama K, Suzuki A, et al. Differentiating benign notochordal cell tumors from chordomas: radiographic features on MRI, CT, and tomography. AJR Am J Roentgenol. 2011;196(3):644-50.

85. Chihara C, Korogi Y, Kakeda S, Nishimura J, Murakami Y, Moriya $\mathrm{J}$, et al. Ecchordosis physaliphora and its variants: proposed new classification based on high-resolution fast MR imaging employing steady-state acquisition. Eur Radiol. 2013;23(10):2854-60.

86. Mehnert F, Beschorner R, Kuker W, Hahn U, Nagele T. Retroclival ecchordosis physaliphora: MR imaging and review of the literature. AJNR Am J Neuroradiol. 2004;25(10):1851-5.

87. Rotondo M, Natale M, Mirone G, Cirillo M, Conforti R, Scuotto A. A rare symptomatic presentation of ecchordosis physaliphora: neuroradiological and surgical management. J Neurol Neurosurg Psychiatry. 2007;78(6):647-9.

88. Park HH, Lee KS, Ahn SJ, Suh SH, Hong CK. Ecchordosis physaliphora: typical and atypical radiologic features. Neurosurg Rev. 2017;40(1):87-94.

89. Ozgur A, Esen K, Kara E, Yencilek E, Vayisoglu Y, Kara T, et al. Ecchordosis physaliphora: evaluation with precontrast and contrast-enhanced fast imaging employing steady-state acquisition $\mathrm{mr}$ imaging based on proposed new classification. Clin Neuroradiol. 2016;26(3):347-53.

90. Lagman C, Varshneya K, Sarmiento JM, Turtz AR, Chitale RV. Proposed diagnostic criteria, classification schema, and review of literature of notochord-derived ecchordosis physaliphora. Cureus. 2016;8(3):e547.

91. Yamamoto T, Yano S, Hide T, Kuratsu J. A case of ecchordosis physaliphora presenting with an abducens nerve palsy: a rare symptomatic case managed with endoscopic endonasal transsphenoidal surgery. Surg Neurol Int. 2013;4:13.

92. Ling SS, Sader C, Robbins P, Rajan GP. A case of giant ecchordosis physaliphora: a case report and literature review. Otol Neurotol. 2007;28(7):931-3.

93. Rodriguez L, Colina J, Lopez J, Molina O, Cardozo J. Intradural prepontine growth: giant ecchordosis physaliphora or extraosseous chordoma? Neuropathology. 1999;19(3):336-40.

94. Kaufman BA, Francel PC, Roberts RL, Argemand E, Park TS, Dehner LP. Chondroid chordoma of the lateral skull base. Pediatr Neurosurg. 1995;23(3):159-65.

95. Rossiello R, Ferrara G, Varricchio A, Baldi A, Motta S, Motta G. Chondroid chordoma of the lateral skull base. ORL J Otorhinolaryngol Relat Spec. 2001;63(2):114-8.

96. Murphey MD, Walker EA, Wilson AJ, Kransdorf MJ, Temple HT, Gannon FH. From the archives of the AFIP: imaging of primary chondrosarcoma: radiologic-pathologic correlation. Radiographics. 2003;23(5):1245-78.

97. Muller U, Kubik-Huch RA, Ares C, Hug EB, Low R, Valavanis $\mathrm{A}$, et al. Is there a role for conventional MRI and MR diffusionweighted imaging for distinction of skull base chordoma and chondrosarcoma? Acta Radiol. 2016;57(2):225-32.

98. Freeze BS, Glastonbury CM. Differentiation of skull base chordomas from chondrosarcomas by diffusion-weighted MRI. AJNR Am J Neuroradiol. 2013;34(10):E113.

99. Stacchiotti S, Sommer J, Chordoma Global Consensus G. Building a global consensus approach to chordoma: a position paper from the medical and patient community. Lancet Oncol. 2015;16(2):e71-83.

100. Guler E, Ozgen B, Mut M, Soylemezoglu F, Oguz KK. The added value of diffusion magnetic resonance imaging in the diagnosis and posttreatment evaluation of skull base chordomas. J Neurol Surg B Skull Base. 2017;78(3):256-65.

101. Tauziede-Espariat A, Bresson D, Polivka M, Bouazza S, Labrousse F, Aronica E, et al. Prognostic and therapeutic markers in 
chordomas: a study of 287 tumors. J Neuropathol Exp Neurol. 2016;75(2):111-20.

102. • Tian K, Wang L, Ma J, Wang K, Li D, Du J, et al. MR imaging grading system for skull base chordoma. AJNR Am J Neuroradiol. 2017;38(6):1206-11. To our knowledge, this is the first study to define imaging characteristics of chordoma which may be used for prognostic purposes.

103. Subhawong TK, Jacobs MA, Fayad LM. Insights into quantitative diffusion-weighted MRI for musculoskeletal tumor imaging. AJR Am J Roentgenol. 2014;203(3):560-72.

104. Abdel Razek A, Mossad A, Ghonim M. Role of diffusionweighted MR imaging in assessing malignant versus benign skull-base lesions. Radiol Med. 2011;116(1):125-32.

105. Ginat DT, Mangla R, Yeaney G, Johnson M, Ekholm S. Diffusion-weighted imaging for differentiating benign from malignant skull lesions and correlation with cell density. AJR Am J Roentgenol. 2012;198(6):W597-601.

106. Khoo MM, Tyler PA, Saifuddin A, Padhani AR. Diffusionweighted imaging (DWI) in musculoskeletal MRI: a critical review. Skelet Radiol. 2011;40(6):665-81.

107. Lang N, Su MY, Xing X, Yu HJ, Yuan H. Morphological and dynamic contrast enhanced MR imaging features for the differentiation of chordoma and giant cell tumors in the axial skeleton. J Magn Reson Imaging. 2017;45(4):1068-75.

108. Essig M, Nguyen TB, Shiroishi MS, Saake M, Provenzale JM, Enterline DS, et al. Perfusion MRI: the five most frequently asked clinical questions. AJR Am J Roentgenol. 2013;201(3):W495-510.

109. Fani M, Nicolas GP, Wild D. Somatostatin receptor antagonists for imaging and therapy. J Nucl Med. 2017;58(Suppl 2):61S-6S.

110. Haug AR, Auernhammer CJ, Wangler B, Schmidt GP, Uebleis C, Goke B, et al. 68 Ga-DOTATATE PET/CT for the early prediction of response to somatostatin receptor-mediated radionuclide therapy in patients with well-differentiated neuroendocrine tumors. J Nucl Med. 2010;51(9):1349-56.

111. Oksuz MO, Winter L, Pfannenberg C, Reischl G, Mussig K, Bares R, et al. Peptide receptor radionuclide therapy of neuroendocrine tumors with (90)Y-DOTATOC: is treatment response predictable by pre-therapeutic uptake of (68)GaDOTATOC? Diagn Interv Imaging. 2014;95(3):289-300.

112. Schaller BJ, Modo M, Buchfelder M. Molecular imaging of brain tumors: a bridge between clinical and molecular medicine? Mol Imaging Biol. 2007;9(2):60-71.

113. Sala E, Mema E, Himoto Y, Veeraraghavan H, Brenton JD, Snyder A, et al. Unravelling tumour heterogeneity using nextgeneration imaging: radiomics, radiogenomics, and habitat imaging. Clin Radiol. 2017;72(1):3-10.

114. Mabray MC, Barajas RF Jr, Cha S. Modern brain tumor imaging. Brain Tumor Res Treat. 2015;3(1):8-23.

115. Gillies RJ, Kinahan PE, Hricak H. Radiomics: images are more than pictures. they are data. Radiology. 2016;278(2):563-77. 